\title{
BCRT response to Moller
}

\author{
D. Gareth Evans
}

Published online: 15 November 2014

(c) Springer Science+Business Media New York 2014

We thank Dr. Møller and colleagues for taking an interest in our paper $[1,2]$. They rightly point out the scarcity of survival data. Both our deaths [1] in the MRI series occurred in BRCAl mutation carriers. This therefore raises concerns over whether MRI may be as effective in BRCAl. Tharmaratnam et al. [2] have assessed their data from their original publication [3] now only for BRCA1 mutation carriers who were unaffected at the time of entry into screening. They again showed relatively poor survival in their MRI-screened series of $73 \%$ at 10 years compared to an almost identical $72 \%$ in the mammography only series. Whilst our projected survival to 10 years in our MRIscreened BRCAl carriers is above $90 \%$, this is based on only 24 cases. We are aware that in the UK, the vast majority of small $<10 \mathrm{~mm}$ lymph node negative high grade triple negative breast cancers receive chemotherapy, but we are not sure this is the case in Norway. It would be helpful to know whether the Norwegian cases received adjuvant chemotherapy as this has been shown to improve survival in BRCAl carriers [4, 5].

Even if some of the poorer survival can be put down to nontreatment with chemotherapy, far more survival data on $B R C A 1$ carriers screened with MRI are required so that

women can make informed choices when opting for MRI surveillance over risk-reducing mastectomy.

\section{References}

1. Evans DG, Kesavan N, Lim Y, Gadde S, Hurley E, Massat NJ, Maxwell AJ, Ingham S, Eeles R, Leach MO, MARIBS Group, Howell A, Duffy S (2014) MRI breast screening in high-risk women: cancer detection and survival analysis. Breast Cancer Res Treat 145(3):663-672

2. Tharmaratnam K, Mæhle L, Møller P. New letter

3. Møller P, Stormorken A, Jonsrud C, Holmen MM, Hagen AI, Clark N, Vabø A, Sun P, Narod SA, Mæhle L (2013) Survival of patients with BRCA1-associated breast cancer diagnosed in an MRI-based surveillance program. Breast Cancer Res Treat 139(1):155-161

4. Robson ME, Chappuis PO, Satagopan J, Wong N, Boyd J, Goffin JR, Hudis C, Roberge D, Norton L, Bégin LR, Offit K, Foulkes WD (2004) A combined analysis of outcome following breast cancer: differences in survival based on BRCA1/BRCA2 mutation status and administration of adjuvant treatment. Breast Cancer Res 6(1):R8-R17

5. Evans DG, Howell A (2004) Are BRCA1- and BRCA2-related breast cancers associated with increased mortality? Breast Cancer Res 6(1):E7

This rebuttal letter refers to the letter to the editor article available at 10.1007/s10549-014-3178-1.

D. G. Evans $(\bowtie)$

Department of Genomic Medicine, Manchester Academic

Health Science Centre, Central Manchester Foundation Trust, St.

Mary's Hospital, Manchester University, Oxford Road,

M13 9WL, Manchester, UK

e-mail: gareth.evans@cmft.nhs.uk 